\title{
Agenda versus agencia: una traducción a política pública del movimiento de los ex braceros en México (1942-1967)
}

\author{
PHILIPPE SCHAFFHAUSER
}

\begin{abstract}
Este artículo versa sobre la construcción de políticas públicas migratorias en perspectiva pragmatista, constructivista e interaccionista. Se centra en el estudio y el análisis de la transformación del movimiento bracero -cuyo origen es la falta de pago de un fondo de retiro campesino- en un programa de atención social a ex trabajadores migratorios mexicanos (1942-1964). Plantea que las políticas públicas que se derivan de la movilización social pueden ser analizadas en tanto interacciones hechas de reclamos, traducción de éstos y constitución de coto de poder para su expresión política y moral, por medio de figuras sociales distintas, como víctimas, portadores, traductores y propietarios de "un problema". En este sentido, el movimiento de los ex braceros constituye un ejemplo claro.
\end{abstract}

PALABRAS CLAVE: Programa Bracero, políticas públicas, movimiento social braceros, interaccionismo simbólico, pragmatismo

Agenda versus Agency: A Translation to Public Policy of the Movement of the Ex Braceros in Mexico (1942-1967)

This article is about the construction of migratory policies in interactionist and pragmatist, constructivist perspective. It focuses on the study and analysis of the transformation of the farm worker movement-whose origin is the non-payment of a rural retirement fund-in a program of social care to former Mexican migrant workers (1942-1964). It considers that public policies that derive from social mobilization can be analyzed as interactions made claims, of the same translation and constitution of reserve power for political and moral reasons, expressed through various social figures as victims, carriers, translators and owners of "a problem". In this sense, the movement of the former braceros is a clear example.

El Colegio de Michoacán, KEYWORDS: program bracero, public policies, bracero social movement, symbolic interactionism, pragmatism 


\section{Introducción}

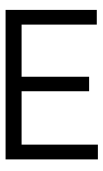

n este artículo, consideraremos cualquier "problema migratorio" como un asunto de construcción social y política. Prácticamente cualquier problema social puede convertirse en un problema público. La importancia de un problema público no es absoluta sino relativa a una serie de parámetros políticos, sociales, morales, culturales, económicos, religiosos, etc., y a interacciones entre agentes grandes, pequeños o medianos, individuales y colectivos. La magnitud de un problema consiste en una construcción social que deviene en la naturalización política de su existencia moral. Por ejemplo, el alcoholismo al volante es, en este sentido, "un problema público" que permite descartar cualquier otro tipo de problemas relacionados con el uso masivo de vehículos particulares como modelo civilizatorio - es decir, moral — para la comunicación y transportación de bienes y personas (Gusfield, 1981). ${ }^{1} \mathrm{El}$ "problema de los braceros" es otro ejemplo cardinal de ello. ${ }^{2}$ El tránsito del uno al otro remite a una situación de selección de un problema entre muchos y de la asunción, no necesaria, del interés social correspondiente a una preocupación local convertida en un problema político magno. Además, partimos de la idea de que, en buena medida, los problemas públicos convertidos en políticas públicas son el resultado de la agencia de movimientos sociales o la

$1 \quad$ No todos los accidentes viales tienen que ver con el consumo de alcohol, pero sí con el estado y el mantenimiento de los vehículos y la red de carreteras, la edad del conductor y su estado anímico, la calidad de la construcción de los coches, las interacciones con otros vehículos y usuarios de los espacios viales.

2 El Día del Bracero se celebra el 29 de septiembre, en México, desde 2001, y en Estados Unidos, desde 2003. Corresponde a la fecha oficial de comienzo del Programa Bracero, caracterizada por la llegada del primer contingente de braceros, conformado por 500 trabajadores, a Stockton, California. 
intromisión de grupos de presión en esferas de poder, lo cual no es la simple traducción política de un pliego petitorio a acciones y programas, sino un proceso sinuoso de negociaciones que transforma un problema social en un problema público y una política pública. Cuando una política pública proviene de un movimiento social, se trata de un acto de creación pública (Joas, 1999; 2002), y cuando se deriva de la intervención e intermediación de un grupo de presión —clubes, banqueros, lobby religioso, etc.- - es un acto de invención pública. Los problemas públicos son creación de soluciones o bien invención de necesidades, por medio de la construcción de políticas públicas.

Nos apoyaremos en la tradición pragmatista y sus autores tempranos, como John Dewey (2003) y George Herbert Mead (1990), para quienes "un problema" es siempre el "asunto de alguien", lo cual significa que no existen problemas en sí o naturales, sino construcciones de problemas situados en espacios sociales y culturales determinados. Dicha tradición filosófica prosperó principalmente en la sociología interaccionista, que constituye la principal fuente de argumentación sociológica en este artículo (Schaffhauser, 2016; Collins, 2009).

Así, muchas políticas públicas se emparentan con la identificación de crisis — sanitaria, financiera, ecológica, migratoria, etc.- y parecen ser respuestas simétricas, naturales y funcionales a “problemas sociales concretos". Esta visión simplista consiste en creer que a cada problema social corresponde una sola y única respuesta en tanto que política pública. Sin embargo, los problemas públicos no son hallazgos sino actos de creación. ${ }^{3}$ Se originan en interacciones complejas y se producen en escalas de observación distintas. Este artículo contribuye a desaparecer esta ilusión y sustituirla con un enfoque pragmatista, constructivista e interaccionista (Becker, 2006), que trata a las políticas públicas como el fruto de interacciones complejas entre públicos organizados e instituciones públicas.

\section{Planteamiento del problema}

El pragmatismo como herencia filosófica ofrece una sensibilidad teórica que favorece la construcción de una perspectiva sociológica centrada en las ideas de procesos morales, pluralidad cultural y comunicación social para estudiar de nuevo temas y problemas sociológicos añejos cuyo epicentro es la anomia, es decir, el deterioro - $\mathrm{O}$ la idea de deterioro- de los vínculos sociales. En este sentido, la contribución de Richard Sennett (2009) al campo de la sociología del trabajo es un claro ejemplo.

Esta investigación ha consistido en recuperar el trabajo de observación directa del movimiento de los ex braceros (1942-1967), ${ }^{4}$ realizado en varios sitios de Michoacán, Zacatecas y el Distrito Federal — hoy Ciudad de México-, entre 2009 y 2014, con la intención de analizar la concepción e implementación del programa de apoyo social a los ex braceros, ideado por el gobierno de Vicente Fox e instrumentado por el régimen de su sucesor, Felipe Calderón. Dicho programa es el resultado de interacciones entre braceros, asociaciones civiles de braceros y autoridades públicas, mediadas por una serie de actores cuyo papel ha consistido en definir cada etapa del proceso de politización e

3

Los pobres no descubrieron escondida la desigualdad socioeconómica un buen día en sitio alguno y tampoco los negros hicieron lo propio con el racismo. Ambos grupos viven situaciones de pobreza o racismo y problematizan el encajonamiento de su existencia en ellas como una fatalidad, una injusticia o una etapa adversa que habrán de superar de manera individual, familiar o colectiva.

4 Existe una polémica en torno a la fecha real de término de los acuerdos braceros. Según Wayne Cornelius y Vernon Briggs (citados en Bustamante, 1976: 27), con base en fuentes del Departamento de Trabajo de los Estados Unidos, hubo 37580 contratos de trabajo firmados después de 1964 y hasta 1967. Hoy varias organizaciones de braceros, como Ex Braceros en Lucha, en Zacatecas, retoman este tema para exigir la inclusión de quienes tengan contratos de trabajo de ese periodo en los programas de atención y apoyo a ex braceros. 
institucionalización del problema bracero. Son tres etapas: la definición-percepción del problema, sus múltiples traducciones y la construcción de un coto público, en el cual y por medio del cual se ha pretendido resolver el problema al acaparar la expresión de su contenido moral y político. La primera etapa descansa, asimismo, en tres operaciones traducidas a verbos de acción: nombrar un problema, culpar a un responsable y pedir justicia (Neveu, 1999: 2). En esta etapa destaca una categoría funcional de sujetos que son "los portadores del problema". A menudo son víctimas directas de sus efectos o pueden ser personas allegadas a éstas. El tránsito de la condición de ser víctima de un problema — catástrofe natural, despido económico abusivo, víctimas de descuidos médicos, personas defraudadas, etc. - a ser portador del problema no es obligatorio ni mecánico. De hecho, podríamos aducir que, en general, hay siempre más víctimas de un problema que portadores en un escenario mediático y político determinado. El paso de una situación a otra es asunto de agencia y constitución de un capital agonístico, una experiencia de protesta y lucha. Así, el movimiento de los ex braceros se conforma de portadores del problema bracero y no de todas sus víctimas. Significa que el movimiento bracero, como cualquier movimiento social, está subrepresentado en relación con la realidad sociológica de su base social. No todas las víctimas, por razones entremezcladas — social, ignorancia, falta de autoestima, carencia de conciencia política y ciudadana, conformismo victimal, etc.—-, se enrolan en las filas del grupo de los portadores de un problema.

La suma de experiencias de sufrimiento social tiende a convertir a sus portadores en un público

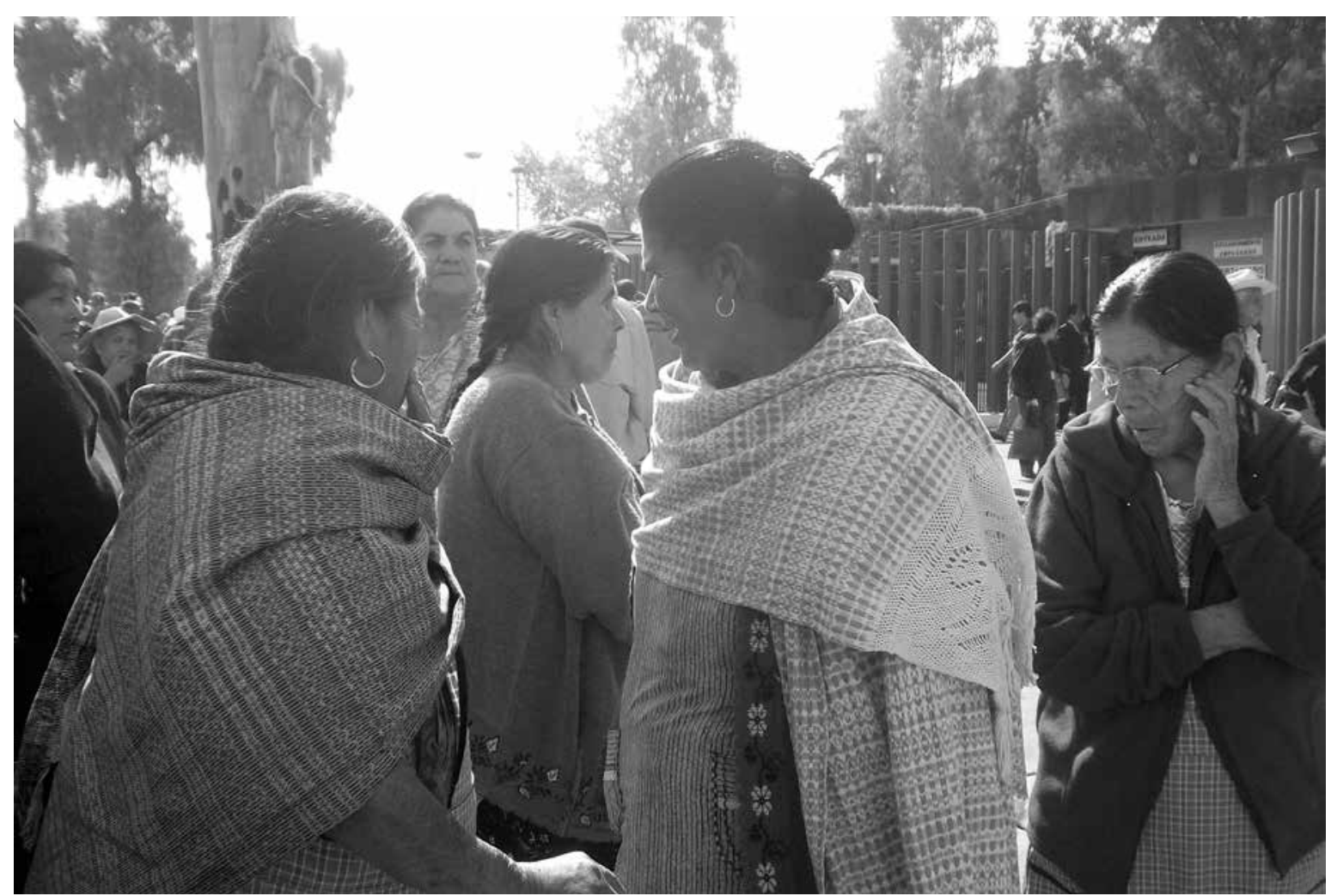

Philippe SchaffHauser • Plantón de la asociación Braceroproa afuera del Palacio Legislativo de San Lázaro, Ciudad de México, 29 de septiembre de 2011. 
agrupado alrededor de un problema socialmente identificado, o al menos en un prepúblico (Park, 1996; Dewey, 2003), mejor dicho, un público en proceso, es decir, en busca de un Estado (Dewey, 2003: 55-67), que se encuentra en espera de conseguir un vocero o traductor, gracias al cual el radio de difusión de "su problema" se extenderá y tocará otras esferas de la opinión pública. La segunda etapa consiste en recoger y traducir el descontento con sus expresiones cacofónicas y emocionales a otro lenguaje, es decir, hacia un discurso abigarrado y secuenciado por guiones sociales propios de mundos distintos: periodismo, activismo, sindicalismo, estética, política y ciencias sociales. Estos guiones deslindan de manera burda un espacio de recepción del malestar, resentimientos e ira que manifiesta la masa de anónimos, y construyen una base para la emergencia de un público cuya columna vertebral es el discurso que arropa su legitimidad.

La interacción entre las víctimas y sus representantes permite a las primeras ascender al rango de público de inconformes, en tanto los segundos se convierten en sus traductores. Esta etapa produce portavoces. Estos signos reemplazan las miles de voces anónimas y prolongan hacia otros ámbitos el mensaje que emana de ellas. La tercera etapa establece el encuentro entre dicho discurso y cotos de poder instituidos — política, economía, religión y academia-, y descansa en una operación de abanderamiento de una causa social cuya legitimidad reside en la existencia de un público. Esto corresponde a una desviación del sentido social original que posibilita la apropiación del discurso y el problema que le corresponde, en un espacio simbólicamente marcado en el que el uso de la palabra se jerarquiza e importa más quién habla y menos de qué y cómo sobre tal o cual problema. Es el espacio de los propietarios de problemas. Existen dos tipos de propietarios: "los auténticos" y "los advenedizos". Los primeros vivieron en carne propia el problema social que los vulneraba y terminan por arrastrarlo como un estigma positivo. Portan ese estigma en sus mentes y cuerpos. Su experiencia social construye su legitimidad. Los segundos se apropian del problema de otros para representar sus intereses. Su legitimidad no radica en su experiencia social directa del problema sino en el valor social asociado a su estatuto en tanto representante del pueblo, autoridad moral, religiosa, intelectual o científica. Asimismo, la figura del experto o perito se suma a la categoría de los propietarios de un problema. Se trata de un personaje advenedizo cuya especialidad — peritaje - construye su legitimidad y posición dentro de la categoría de los propietarios. Hoy, el sociólogo, el economista y el psicólogo se han convertido en propietarios de problemas sociales. Canjearon sus dudas científicas por la afirmación moral de la autoridad social que sostienen. Son capaces — es decir, se sienten habilitados- de hablar de cualquier problema y dictar sentencias moral-epistémicas al respecto. En resumen, en esta última etapa asoma un proceso de asunción de papeles (Mead, 1990: 283) en el que "portadores" y "traductores" pueden convertirse en "propietarios de un problema” y afianzar su carrera protagónica.

En general, un problema público se deriva de la transformación de un hecho social en motivo de pugna: los braceros, como grupo de veteranos migratorios, se convierten en un grupo de ciudadanos organizados que luchan por su dignidad como deuda moral del Estado mexicano hacia ellos. Esta problematización del movimiento de los ex braceros forma parte de una reflexión más amplia sobre políticas públicas en general, en la que el tema migratorio es sólo un asunto a atender entre otros. Esta investigación se centra en el estudio de las interacciones sociales portadoras de valores, intereses y emociones y no adopta ninguna de las posiciones de los sujetos de carne y hueso involucrados, aunque en términos metodológicos adopta la postura de los braceros y su perspectiva desde su ventana etaria y rural. Por último, este trabajo se desprende 
de manera crítica de las investigaciones tradicionales que estudian el tema de las políticas públicas y se centran en destacar su lógica interna y la diferencia entre sus intenciones abiertas y sus resultados tangibles, lo cual se cristaliza en la cultura científica y burocrática del diagnóstico (Neveu, 1999: 3). Aquí no se trata de afirmar si una política pública es buena o mala, congruente o no con sus objetivos, sino de insistir en su artificialidad y resaltar su concepción parcial en relación con el problema que pretende atender.

Para lograr el cometido de esta investigación, examinaremos de cerca cómo el Estado fue construyendo una política pública entre 2005 y 2012, para atender la situación socioeconómica de ex trabajadores migratorios mexicanos, en aras de reparar la injustica histórica de la que fueron objeto como consecuencia del Programa Bracero (1942-1967). ${ }^{5}$

\section{Orígenes y constitución del movimiento de ex braceros}

Desde mediados de la década de 1990, el movimiento de los ex braceros empieza a surgir en varios puntos de la república. Varios grupos y asociaciones han abanderado esta causa. En Michoacán y otros estados del país, incluso en Estados Unidos, destacó la organización Braceroproa, ${ }^{6}$ liderada por Ventura Gutiérrez, ciudadano mexicano-estadounidense originario de Puruándiro, Michoacán. En Zacatecas, la asociación civil Ex Braceros en Lucha, disidencia de Braceroproa, se ha caracterizado por ejecutar propuestas originales, como la implementación estatal de un fondo propio de ayuda social para braceros zacatecanos, y ser una de las principales organizaciones que dieron lugar a la creación de la Coordinadora Binacional de Ex Braceros (Cobieb), creada para contravenir la política de desatención al tema de los ex braceros por el gobierno del presidente Enrique Peña Nieto. ${ }^{7}$
El llamado "problema bracero" se relaciona con un asunto de peculado, ya que, durante el programa laboral, los braceros cotizaron para un fondo de retiro campesino que se gestionó primero en Estados Unidos, con la institución bancaria Wells Fargo, y después, mediante una transferencia financiera

El 23 de julio de 1942, en la ciudad de Monterrey, los presidentes Frank D. Roosevelt y Manuel Ávila Camacho firmaron el Mexican Farm Labor Program Agreement, conocido como "programa bracero". El primer contingente de 500 braceros descendió de un tren en Stockton, California, el 29 de septiembre de 1942. El Congreso de Estados Unidos dio cuerpo jurídico al programa con la Public Law 45, el 29 de abril de 1943. Se acordó un descuento de 10\% en la nómina de los ingresos percibidos de cada bracero para conformar un fondo de ahorro campesino, destinado a facilitar el retorno de los braceros a México y la compra del apero y material agrícola. Este fondo fue gestionado por el banco Wells Fargo de Estados Unidos, que los transfirió al Banco de Crédito Rural (Banrural) de México. En total se firmaron 4646199 contratos, correspondientes a la mano de obra de 3233755 braceros. La administración displicente de este fondo motivó el surgimiento del movimiento de los braceros en 1998 a ambos lados de la frontera.

6 Conocida también como Frente Nacional Braceroproa, A. C., que originó la creación de asociaciones civiles como la Asociación Nacional de Adultos Mayores (ANAM) y el Centro Jalisciense de Adultos Mayores y Migrantes, bajo la responsabilidad de Gilberto Parra, hijo de ex bracero. Cabe señalar que después de un conflicto entre Ventura Gutiérrez y Gilberto Parra, éste fue excluido de manera oficial de la organización Braceroproa; sin embargo, siguió utilizando el acrónimo para formar otro grupo de ex braceros en Jalisco. El nombre "Braceroproa" es un claro guiño al escándalo provocado por el Fondo Bancario de Protección al Ahorro (Fobaproa) para rescatar el sistema bancario mexicano, durante la presidencia de Ernesto Zedillo.

7 En realidad, la instrumentación del programa de apoyo social en el sexenio de Enrique Peña Nieto ha tomado un giro jurídico y legal, pues los más de 40000 expedientes que contaron con el visto bueno de la administración al finalizar el mandato de Felipe Calderón están pendientes y algunos de sus beneficiarios emprendieron una acción legal para recuperar el dinero del apoyo social prometido, lo cual ocurrió en diciembre de 2015 , después de tres años de pleito, con la indemnización de poco más de 7000 braceros y sus familiares. Esta cantidad corresponde a 17.5\% de los 40000 expedientes pendientes. 


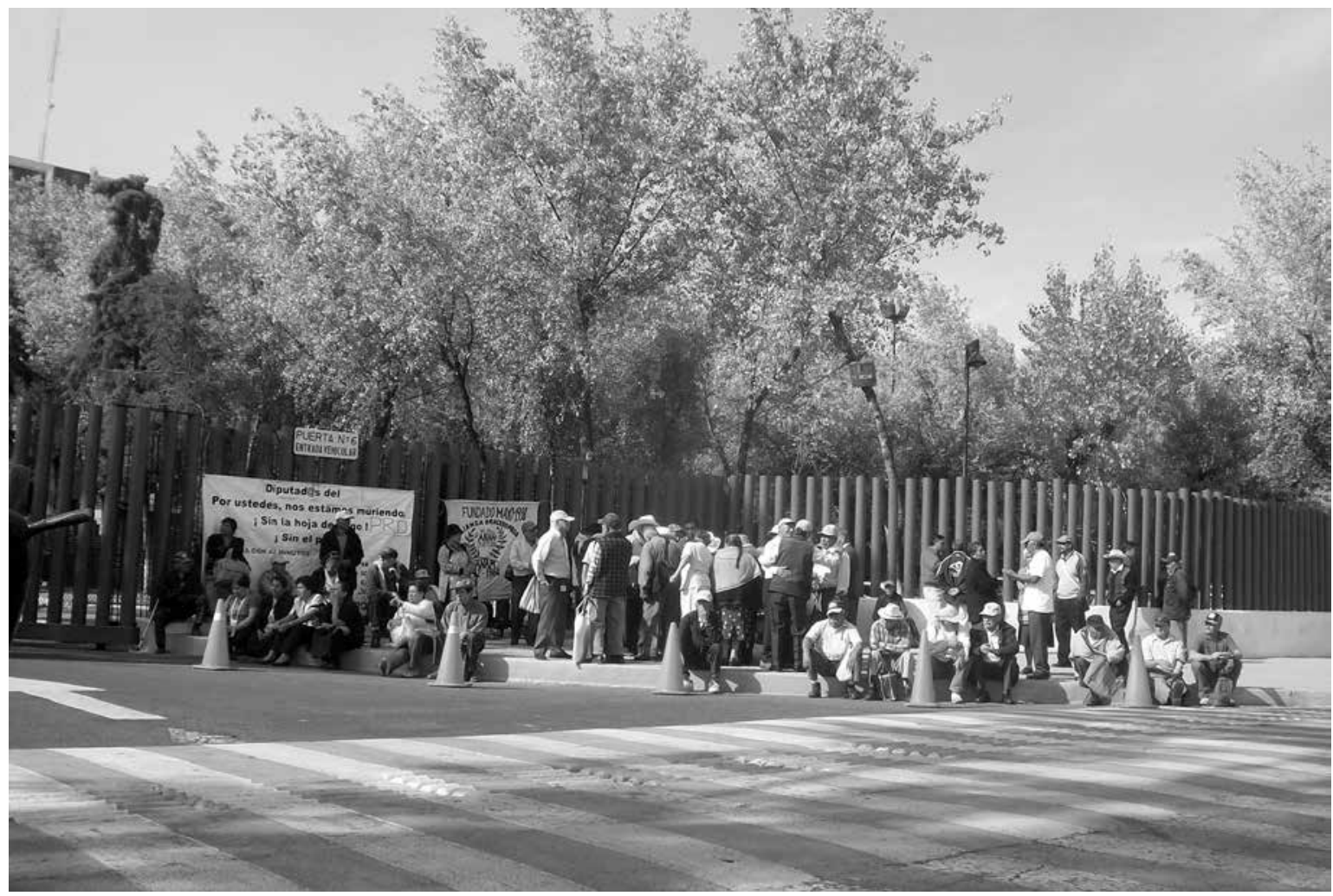

PhilipPE SchaffHAuSER • Plantón de la asociación Braceroproa afuera del Palacio Legislativo de San Lázaro, Ciudad de México, 29 de septiembre de 2011.

al otrora Banco de Crédito Rural (Banrural). Hoy nadie puede decir con certeza qué fue de este dinero, cómo se gastó o cómo se desvió de su finalidad inicial, y de qué se trata con exactitud, toda vez que incluye los intereses generados — anatocismo- desde 1964, cuando culminó "oficialmente" el Programa Bracero. ${ }^{8}$ Todo lo anterior corresponde a una suerte de etnografía sobre lo que es una estafa social y financiera. Conforme fue creciendo la inconformidad de los ex braceros en el ámbito nacional, se suscitó la creación local de organizaciones de braceros que pugnaron por sus derechos sociales. A la postre, éste fue el impulso para el surgimiento de un movimiento nacional de braceros, durante el sexenio de Vicente Fox. En la administración del presidente Calderón, comenzó un sistema de indemnización diseñado en la administración anterior. En diciembre de 2005, se creó el fideicomiso 2106 —rebautizado 10230 en 2012-, "Fondo de apoyo social para ex trabajadores migratorios mexicanos", dependiente de la Secretaría de Gobernación (Segob), encargado de

Según un estudio de la Cámara de Diputados del Congreso de la Unión, realizado por la Comisión Especial para Dar Seguimiento a los Fondos de los Trabajadores Mexicanos Braceros, el Estado mexicano tendría que pagar la cantidad astronómica de 122883 millones de pesos a 3233755 beneficiarios, para apoyar a todos los braceros del país con un pago individual -fruto de una negociación entre el gobierno federal y organizaciones de braceros- de 38000 pesos (CEFP, 2008). Hasta ahora, y según cálculos realizados en el marco de esta investigación, entre 2005 y 2011, las autoridades federales han pagado 7652 millones de pesos a 220521 braceros. Cabe señalar que dicha cantidad es sólo un apoyo y no corresponde al monto real del fondo de retiro campesino y los intereses que generó. 
supervisar y tramitar la indemnización, y realizar el pago a los beneficiarios.

Sin embargo, este panorama institucional no ha sido tan idílico, pues hubo numerosas cortapisas para atrasar el pago de la indemnización: falta de preparación del personal administrativo, cambio repentino de las reglas de operación en 2009 - que implicaron fraccionar el pago en anualidades por un monto de 4000 pesos-, falta de coordinación entre los tres niveles del poder ejecutivo de la nación -municipal, estatal y federal-y las instituciones involucradas: el fideicomiso, las secretarías locales y el servicio de correos y telégrafos de México, encargado del pago.

Además, con la creación de este mecanismo de indemnización se avaló una serie de omisiones en la atención institucional del problema bracero:

- Se descartó el uso del recurso jurídico para fincar responsabilidades penales contra quienes hubieren incurrido en un fraude en relación con la administración del fondo de retiro campesino.

- Se eliminó, por lo tanto, la idea de regresar a los beneficiarios legales la totalidad del dinero correspondiente al fondo. Por ello se habla, con harta sutileza, de "indemnización" y no de "reembolso".

- La administración fija, sin concertación previa con las organizaciones de braceros, los requisitos para solicitar la indemnización, lo que deja en la indefensión a cientos de miles de braceros que no tienen más justificación de su condición de bracero que su memoria y la de sus compañeros testigos. $^{9}$

- Esto significa que el Estado mexicano reconoce de manera parcial su responsabilidad en el problema bracero y establece quiénes han sido braceros y quiénes no (Schaffhauser, 2012: 211-245).

Con todo, a finales de 2012 se indemnizó con un pago de 38000 pesos a poco más de 220000 braceros y sus derechohabientes — viudas o hijos-, lo que corresponde a menos de 10\% del total de braceros que hubo en la historia de ese acuerdo laboral bilateral.

Ahora bien, planteado el escenario, queda señalar los elementos que apuntan hacia la transformación del movimiento de los braceros en un programa gubernamental, esto es, la creación del "Fondo de apoyo social para ex trabajadores migratorios mexicanos", en 2005.

Para integrar la lista de beneficiarios del programa, cada bracero o familiar tuvo que cubrir una serie de requisitos para acreditarse como tal, lo que dejó fuera a cientos de miles de braceros que siguen siendo beneficiarios potenciales. El programa construye, entonces, una frontera identitaria en torno al derecho o no de haber sido bracero. El testimonio directo no vale porque sólo cuentan ciertos documentos determinados por la Segob para acreditar la identidad del bracero..$^{10}$ Para las autoridades actuales, ser bracero consiste en haber recibido el apoyo social que brinda el fideicomiso. Los demás no tienen existencia legal, y por lo tanto, no son beneficiarios. Se les niega la autenticidad de su identidad social como braceros. En este sentido, cada política pública social da un rostro, es decir, una legitimidad política y moral, a quien es considerado beneficiario de ella. De ahí que exista una relación estrecha entre políticas públicas e identidades sociales. Cada política pública tiende a construir un público cautivo y lo encierra en fronteras morales e institucionales, es decir, en una solidaridad instituida.

9 En este sentido, el estado de Zacatecas, desde 2010, y con el empuje de organizaciones de braceros locales, ha sido pionero en la materia al proponer un sistema de indemnización estatal con base en entrevistas para determinar la condición del solicitante a partir de su testimonio oral.

10 Contratos laborales originales, talones de cheque, credenciales - micas-y credenciales de elector. 
Para efecto de sintetizar las principales etapas que se suscitaron en el movimiento de ex braceros, a continuación se presenta una cronología: ${ }^{11}$

- 1942-1967. Programa Bracero. El 4 de agosto se firmó un convenio bilateral laboral entre México y Estados Unidos para la contratación de trabajadores agrícolas mexicanos. En su fase inicial (1942-1946), el programa tenía dos vertientes económicas: la agricultura y el sistema ferrocarrilero estadounidense. La vertiente social del programa consistió en la creación de un fondo de ahorro campesino para el retiro de los trabajadores agrícolas. Su gestión implicó la participación conjunta de bancos estadounidenses y mexicanos.

- 1967-1995. Periodo de silencio y olvido del tema de los braceros. Se refiere a lo que Robert Proctor (2008) llama agnotología, es decir, la construcción institucional de la ignorancia social. Los acuerdos ratificados por ambos gobiernos en materia de pago de un fondo de retiro no se cumplieron a cabalidad, sólo unos cuantos braceros pudieron cobrar su pensión. El problema bracero era entonces endémico y se ubicaba principalmente en las zonas rurales del país. Sin embargo, a partir de comienzos y mediados de la década de 1990, surgieron grupos y organizaciones locales y regionales de ex braceros cuya presión social hacia las autoridades terminó por llamar la atención de algunos traductores: periodistas, académicos, activistas y políticos, entre otros.

- 2001-2012. Bajo la presión de organizaciones de braceros y gracias a la labor de traductores, el gobierno federal y las instituciones del Estado terminaron por poner atención al problema de los ex braceros. Primero se decidió la instalación de una comisión parlamentaria especial para dar seguimiento a los fondos aportados por trabajadores mexicanos braceros. Se conformó por representantes de los principales institutos políticos representados en la Cámara de Diputados. En 2003, se llevó a cabo una reunión entre los miembros de esa comisión y representantes de la Segob, de la Secretaría de Relaciones Exteriores (SRE), Banrural y organizaciones de braceros. Acordaron levantar un padrón de los braceros que laboraron entre 1942 y 1946, brindar asistencia médica a los braceros y sus cónyuges, y fincar las bases para la creación de un programa de atención especial. El 25 de mayo de 2005 se aprobó la ley para crear el fideicomiso que administra el fondo de apoyo social para ex trabajadores migratorios mexicanos. En noviembre de ese año, se publicaron las reglas de operación del programa y se planteó el levantamiento de otro padrón de braceros en mesas receptoras en cada estado de la federación. El gobierno de Felipe Calderón continuó con la implementación de este programa de apoyo social. Tras una serie de vicisitudes sobre el pago a los braceros - en una sola exhibición de 38000 pesos o con anualidades de 4000 pesos — y vericuetos legales, ${ }^{12} \mathrm{el}$ programa indemnizó en 2012 a 222521 braceros o derechohabientes, con poco más de 7500 millones de pesos.

- 2013 a la fecha. El gobierno de Enrique Peña Nieto decidió de manera unilateral no prolongar el programa de apoyo social. Así, desatiende los acuerdos tomados por su antecesor y niega el pago a más de 40000 beneficiarios que cumplieron con los requisitos del programa de apoyo social y

11 Elaborada por el autor, con base en material de trabajo de campo e información de sitios internet sobre la historia de los braceros y archivos de organizaciones de braceros y notas periodísticas, principalmente.

12 Al recibir su pago, a veces tras una larga espera de varias décadas, se le hacía firmar al bracero una carta en la que renunciaba a demandar al Estado por el pago completo de su pensión. Este trámite era obligatorio. 
no alcanzaron a recibir su pago antes del término del sexenio de Felipe Calderón. Las principales organizaciones de braceros se agruparon en la Cobieb en diciembre de 2012 y desde entonces emprendieron acciones sociales y legales ${ }^{13}$ para que el gobierno federal reconsiderara su posición al respecto. En este sentido, el 7 de diciembre de 2015, después de un largo pleito jurídico, 7033 braceros o derechohabientes recibieron la cantidad de 38000 pesos para resarcir su situación.

\section{La vulnerabilidad social como problema público o la construcción política del movimiento de ex braceros}

Como señalan los pragmatistas, como Dewey (2003: 195-197), o los sociólogos, como William Felstiner, Richard Abel y Austin Sarat (1980-1981), y Robert Park (1996), la primera etapa de este proceso consiste en identificar quiénes son los portadores del problema, es decir, en tanto sujetos integrantes de una masa de anónimos que empiezan a comportarse como un público. La masa de la cual forman parte los ex braceros corresponde al anonimato del mundo rural mexicano y el campesinado en general, pensados en categorías intelectuales y urbanas. Muchos de ellos eran jornaleros cuando se fueron a Estados Unidos. Otros no habían completado los grados de la escuela primaria. Algunos no sabían leer ni escribir y firmaban con una cruz los contratos para ir a trabajar a Estados Unidos. Por lo tanto, muchos de ellos no estaban al tanto de sus derechos sociales. Su conciencia ciudadana era escasa o estaba en ciernes. Su condición de átomo de cuadrillas de trabajadores agrícolas se transformó en una conciencia social con agencia propia después del Programa Bracero y de un largo proceso de madurez emocional y familiar, entre 1964 y 1995, aproximadamente. Los portadores del problema bracero son sus primeros protagonistas, es decir, los propios braceros y sus familiares. Estos últimos son a menudo quienes llevan el caso y están pendientes de él: integran la información en el expediente, se trasladan a los centros de atención a braceros, argumentan los elementos presentados ante la administración a cargo, asisten a las asambleas de información y acciones a las que convocan las organizaciones de braceros, participan ocasionalmente en foros sociales y académicos sobre el tema, toman parte de las acciones y movilizaciones que tienden a ejercer una presión sobre el gobierno para agilizar soluciones para el conflicto. Los propios braceros procuran involucrarse en toda esta agenda, pero lo logran a duras penas, porque son pobres, están cansados y muchos de ellos padecen enfermedades crónicas.

Según la asociación Braceroproa, cada día fallecen 14 ex braceros (Schaffhauser, 2011: 30). Dada la edad avanzada de muchos de ellos, la constitución y la representación de un público bracero tienen mucho que ver con quienes han heredado esta causa localmente. Significa, por ejemplo, que muchos de los líderes de organizaciones sociales de apoyo a braceros no son sino sus familiares - por lo general, hijos o nietos- y el resto lo conforman activistas o simpatizantes de esta bandera. Estos representantes constituyen una primera capa de traductores del problema bracero a otra esfera de comunicación, como la prensa, y de ahí, la opinión pública regional o nacional, el sector académico, y por último, el medio político. Ser vocero de una organización de braceros consiste en traducir a otro lenguaje las peticiones y reclamos que expresa el público bracero. Vemos aquí que la frontera entre "portadores" y "traductores" es muy porosa. De ahí surge la necesidad de establecer una distinción para el caso estudiado entre "portadores cercanos" y "portadores

Como la marcha histórica de braceros a Nueva York y Washington, en 2013, y la entrega de una carta a Barack Obama en el marco de la reunión cumbre México-CanadáEstados Unidos, celebrada en Toluca, en febrero de 2014. 
lejanos". Los primeros son familiares de ex braceros, lo cual implica vínculos de sangre y una suerte de solidaridad mecánica — directa e intersubjetivacon el tema bracero. Los segundos son sujetos externos al público de braceros, que expresan sensibilidad e interés por involucrarse en esta causa. Surge otro elemento de análisis: la transformación de una masa de veteranos migratorios en el público de braceros posibilitó la producción de sus propios representantes, es decir, "sus traductores", y llamó la atención de personas en un principio externas a este público, que con el paso del tiempo terminaron siendo adoptadas, y algunas elegidas por los braceros, para representar sus intereses (Schaffhauser, 2012: 220-221). He ahí una distinción clara entre la conformación de la organización Braceroproa, como un público de braceros y como organigrama representativo que corresponde a familiares de braceros, y la asociación de Ex Braceros en Lucha de Zacatecas, cuyos principales líderes proceden del activismo local y no tienen parientes que hayan sido braceros.

Es preciso señalar que toda traducción, si bien transpone una idea de un código lingüístico a otro, implica también una pizca de tergiversación del significado original asignado a la expresión original del problema. Traducción rima con adaptación y alteración, porque la acción de traducir es un acto situado dotado de interés. La traducción libre y natural no existe, siempre tiene una orientación y un fin por más loable que sea. Esta condición tiende a crear y reforzar el poder de quien cuenta con la capacidad y la legitimidad para ser "traductor". A menudo, el grupo de inconformes busca una solución a sus quejas, en tanto que el líder se empeña, además de lo anterior, en afianzar su posición y prolongar su papel. Esta situación se agudiza cuando "el traductor del grupo" no es un emisor esporádico cualquiera sino un agente especializado en descifrar y transponer la glosa social del grupo por y para el cual pretende actuar. Estos últimos elementos indican una clara tendencia en la que la carrera del "traductor" lo conduce a ingresar al campo moral de "los propietarios de problemas" (Becker, 2006: 167-182). Buena parte de la justificación moral de éstos tiene que ver con su pasado y su compromiso como traductores del grupo. Esto les permite valerse del conocimiento que forjaron en el día a día de los problemas enfrentados por el grupo. Su legitimidad descansa en su experiencia personal directa. Algo equiparable sucede con los ex braceros, "los traductores de sus problemas" y "los propietarios de los problemas". Si examinamos la carrera de Ventura Gutiérrez Méndez (2011), existen muchas evidencias de lo anterior:

También quisiera decir que en este momento somos una asociación civil Asamblea Nacional de Adultos Mayores y Braceroproa, pero iniciamos como un movimiento social con una organización con base en California, donde yo me crie. Nací en Puruándiro, Michoacán, pero me crie en Coachella, California, y sin mucho detalle, terminé la Universidad de California en Riverside como sociólogo y maestro de primaria, que era la profesión que ejercía antes de prometerle a mi abuelita Lucía Méndez, en marzo de 1998, después de un evento en Morelia, Michoacán, donde nos acompañó el ex senador Lázaro Cárdenas Batel, ex gobernador de Michoacán —ya que el ingeniero Cuauhtémoc Cárdenas no nos pudo acompañar porque era gobernador del Distrito Federal y optó por no ir a territorio de otro gobernador y mandó a su hijo para apoyarnos-, en un primer evento para establecer un movimiento a favor de los migrantes que se llama Aquí y Allá, y ahí nace la causa del movimiento de los ex braceros el 15 de mayo de 1998, en Puruándiro, Michoacán, encabezada por su servidor y cuatro ex braceros de ese municipio, tres todavía viven, uno ya falleció.

En este testimonio encontramos elementos no sólo sobre cómo se fue conformando, casi de manera 


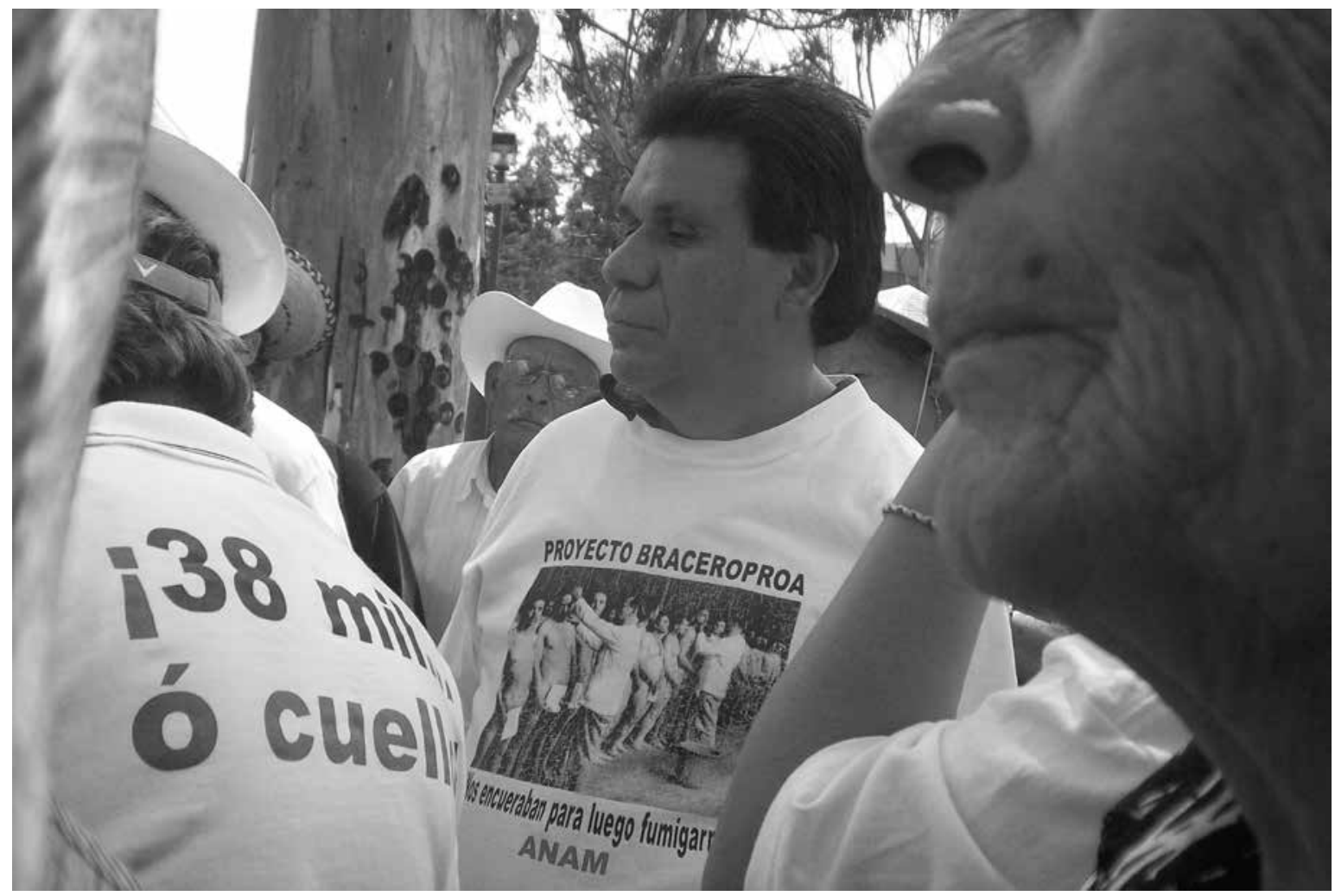

PhILIPpe SchaffHAuSER • Plantón de la asociación Braceroproa afuera del Palacio Legislativo de San Lázaro, Ciudad de México, 29 de septiembre de 2011.

mitológica, la asociación Braceroproa, sino también acerca de cómo empezó la carrera de Ventura Gutiérrez: primero, como portador del problema de un ex bracero - el que le encomendó su abuelita, para reparar la injusticia que sufrió su abuelo-; segundo, en tanto traductor del problema de los ex braceros de Puruándiro y otras partes del país, y por último, en su calidad de portavoz de los ex braceros, que lo condujo a ingresar al campo de "los propietarios del problema de los braceros en México". En este grupo encontramos representantes políticos de varios institutos políticos: la diputada federal Hilaria Domínguez Arvizu, del Partido Revolucionario Institucional (PRI) de Sinaloa; el diputado federal Samuel Herrera Chávez, del Partido de la Revolución Democrática (PRD); Amalia García, del PRD y ex gobernadora del estado de Zacatecas; José Carlos
Luna Salas, del Partido Acción Nacional (PAN), Sergio Acosta Salazar y Pedro Porras Pérez, diputados federales por el PRD; Lázaro Cárdenas Batel, del PRD y ex gobernador del Estado de Michoacán, o Enrique Bautista Villegas, del PRD de Michoacán, entre otros. ${ }^{14} \mathrm{Al}$ mismo tiempo, encontramos líderes sociales que forman parte del debate sobre los ex braceros y ostentan su calidad de propietarios. Es el caso de Gilberto Parra, quien fue entrevistado por la periodista Carmen Aristegui. ${ }^{15}$ Sin embargo, y a

14

Sergio Acosta Salazar y José Carlos Luna Salas fueron integrantes de la Comisión Especial para Dar Seguimiento a los Fondos de los Trabajadores Mexicanos Braceros, entre 2000 y 2003.

15 El 3 de mayo de 2010, en las instalaciones de Radio Metrópoli. 
diferencia de muchos políticos y otros líderes de la causa bracera, Gilberto Parra y Ventura Gutiérrez aparecen como "auténticos propietarios", ya que obtuvieron, con creces, un lugar entre otros propietarios del problema bracero. Sendas trayectorias se convirtieron en un argumento retórico de peso para justificar esa tenencia y respaldar sus acciones al frente del Centro Jalisciense de Adultos Mayores y Migrantes y el Braceroproa, respectivamente.

En realidad, el conflicto bracero empieza como una suerte de cruzada familiar por la dignidad de quien fuera el jefe de familia y se sacrificara por su bienestar. En este sentido, portar un problema consiste en cargar consigo los mismos valores experimentados emocionalmente. En el otro extremo del tablero de ajedrez de las luchas sociales en este país, el tema bracero en el medio político, es decir, entre los institutos políticos mexicanos, ha fijado una línea divisora entre el PRI y el Partido Verde Ecologista de México (PVEM) frente a otros, como el PRD, el recién formado Movimiento Regeneración Nacional (Morena) y el PAN, pues los primeros son tangencialmente renuentes para atender el problema, en tanto que los segundos lo han considerado de suma importancia. No hay que perder de vista que el problema bracero no transcendió durante varias administraciones y gobiernos del PRI, entre 1964 y 2000. Han sido, finalmente, los gobiernos panistas quienes han dado "solución" al conflicto, aunque han buscado mecanismos políticos y jurídicos para minimizar el costo financiero del programa de atención a braceros y morigerar el papel del Estado mexicano en el asunto.

Uno de los pilares del proceso de selección temática, que convierte la emigración en un asunto controversial y punto obligatorio de la agenda política de hoy, tiene que ver con la estigmatización de los sujetos portadores de los signos de la migración: los propios emigrantes, las organizaciones criminales que lucran con la emigración, los agentes migratorios de los Estados-nación, etc. Lo anterior ha provocado una suerte de esquizofrenia institucional. Por un lado, el actuar del Estado se vuelve "líquido" cuando se trata de brindar atención directa e inmediata a las situaciones de desamparo social en las que se encuentran poblaciones de emigrantes y refugiados, y por el otro, "sólido", al momento de custodiar las fronteras nacionales, en aras de la defensa emblemática de la soberanía e identidad nacionales.

Bajo esta óptica escindida, emigrar no crea derechos sociales, pero sí simpatías repentinas, y alimenta, a menudo, las suspicacias y el desdén institucionales. Los braceros y su movimiento social han recibido muestras de simpatía y solidaridad por parte de la ciudadanía, y han puesto de manifiesto actitudes de apatía hacia ellos y en ocasiones de franco rechazo.

Ante estas tendencias sociales y políticas en las sociedades contemporáneas y en México en particular, cabe preguntarse, ¿cómo se articulan políticas públicas y problemas migratorios, en especial las que atienden la situación de los braceros? Asimismo, ¿cómo las políticas migratorias incluyen o superan el problema que consiste en recuperar de manera simbólica sus beneficiarios y eliminar las connotaciones que los construyen como chivos expiatorios, culpables y víctimas al mismo tiempo? Por último, ¿cómo logran tomar en cuenta, en su concepción y diseño, la participación de los propios braceros? Un elemento de respuesta a esta última pregunta tiene que ver con la construcción del problema bracero, por medio de la agencia de sus portadores. A partir de esta base, es posible cerciorarse de los sesgos, manipulaciones, giros, vuelcos y desviaciones en la manera en que se fue concibiendo e implementado el programa de apoyo social entre 2001 y 2012.

A continuación, presento el testimonio de un integrante de la asociación zacatecana Ex Braceros en Lucha, quien describe aspectos del momento en que se encontraban los miembros, es decir "los portadores del problema", entonces en busca de traductores para expresar sus reclamos: 
En el mes de septiembre de ese año, del 2007, me proponen una propuesta [sic]. Que viene el comandante Marcos y que me va a dar la audiencia, y a mí me dio mucho gusto, en el municipio de La Blan$\mathrm{ca},{ }^{16}$ ahí vino el comandante Marcos, pero luego [...] voy a decirle que me haga el favor de prestar atención sobre cómo estamos, ¿verdad? Supuestamente, yo le iba a hablar [de] que yo quería a los compañeros Efraín Arteaga y Mauricio Maldonado, porque queríamos que ambos fueran nuestros líderes, pero el comandante Marcos nos mandó a la chingada. Dijo que no, porque era asunto - fijense cómo me respondió-, que no, porque era asunto federal y que él con lo federal no se metía. Oiga, pues son líderes, son defensores. ¿A quiénes chingados defiende? Fíjense bien, fijense bien, la estrategia de los gobiernos [...]; para mí, Marcos es igual que cualquier gobernante porque es un estafador. Pues ahí está porque le dan lana, pero de defensa no tienen ninguna. Bueno, digo, ahí me [...] demostró que no, porque yo quería que él me echara la mano con que "me prestara" estos líderes, que yo, estos líderes, yo sé que son chingones, son buenos y yo lo vi. Entonces, cuando el comandante Marcos me dijo que no porque es asunto federal y él no se metía en lo federal, que por lo tanto no (entrevista con integrante de Ex Braceros en Lucha, Zacatecas, 18 de febrero de 2012).

Este testimonio desvela muchas aristas para el análisis del problema que nos ocupa. Tiende a inducir la idea de que son los portadores del problema quienes buscan a sus líderes y sus traductores, y no al revés. Éstos son la hechura de aquéllos. Ser lídertraductor implica aceptar obligaciones que giran en torno al tema de la rendición de cuentas, la lealtad al mandato asignado, así como el encargo moral de no tergiversar la traducción de los intereses de "los portadores" a otros espacios sociales y políticos. El testimonio insiste, en este sentido, en el tema delicado de la selección de "traductores" apropiados.
La misma situación ocurre cuando un movimiento social busca tener más audiencia y resonancia, y por lo tanto cuida mucho a qué periodistas acudir para dar una entrevista o a qué investigadores se les puede tener confianza para permitir que estudien el movimiento y divulguen aspectos de él. A pesar de que los portadores rara vez actúan al unísono y manifiestan con frecuencia intereses y objetivos distintos, todos buscan que se respete la línea moral del movimiento en el cual se involucran. Dicha línea, a menudo, es un imaginario de valores y una lista incompleta de reclamos, no siempre fruto de una concertación escrupulosa. El movimiento de los ex braceros, es decir, el movimiento de los portadores del problema bracero, no escapa al dictamen de esta sensibilidad social. La invitación frustrada al subcomandante Marcos también es muestra de la voluntad de ampliar el espacio de recepción y debate del problema bracero. Su traducción a movimiento social no es suficiente y requiere sumarse al esfuerzo y dinámica producidos por otras protestas sociales, como la del Ejército Zapatista de Liberación Nacional (EZLN) o el Sindicato Mexicano de Electricistas (SME) de la otrora Compañía de Luz y Fuerza. ${ }^{17}$

Desde el otro lado de este proceso de construcción de una política pública de atención a los ex braceros, es interesante ver su falta de representación en las instancias creadas para atender el problema. El comité técnico del fideicomiso que supervisaba y administraba el fondo de apoyo social estaba conformado por funcionarios de las secretarías de Gobernación, Relaciones Exteriores, Hacienda y Crédito Público (SHCP), Desarrollo Social y de la Función Pública, entre 2005 y 2012. Otro agente a

\footnotetext{
16 Denominación coloquial de la cabecera del municipio zacatecano General Pánfilo Natera.

17 Este sindicato se ha solidarizado en repetidas ocasiones con el movimiento de los braceros de Zacatecas, con apoyo material y logístico para llevar a cabo sus protestas y acciones.
} 
cargo de la implementación de este programa fue la Comisión Especial para Dar Seguimiento a los Fondos de los Trabajadores Mexicanos Braceros, que se convirtió en una instancia con la cual las organizaciones de braceros cabildearon y negociaron, ya sea de manera directa o en reuniones, foros o consultas a diputados que pudieran interceder a favor ante ella. La academia, mediante la organización de foros o coloquios sobre el tema bracero, ${ }^{18}$ ha constituido otro ámbito y se ha convertido en un espacio de difusión de la causa de los braceros.

Los traductores del problema bracero - líderes de organizaciones, activistas, intelectuales y académicos - tienen que interactuar entre estos espacios sociales y políticos. Entre ellos, las reglas y el juego de lenguaje cambian, y opera la distorsión tan temida por el integrante de la asociación zacatecana de ex braceros. He ahí el espacio de los propietarios del problema bracero. Algunos recurren al argumento de la filiación "mi padre o mi abuelo fue bracero" para justificar su entereza e interés en el asunto. Pero el movimiento de ex braceros no es una familia extensa sino un movimiento de protesta. De ahí se deduce que los portadores del problema bracero no tienen control ni incidencia en los

18

Cabe señalar la organización de un foro sobre braceros en El Colegio de Michoacán, en 2008, y la celebración del I Coloquio Internacional sobre el Programa Bracero en el Centro de Investigaciones sobre América del Norte, de la Universidad Nacional Autónoma de México, el 29 y 30 de septiembre de 2011.

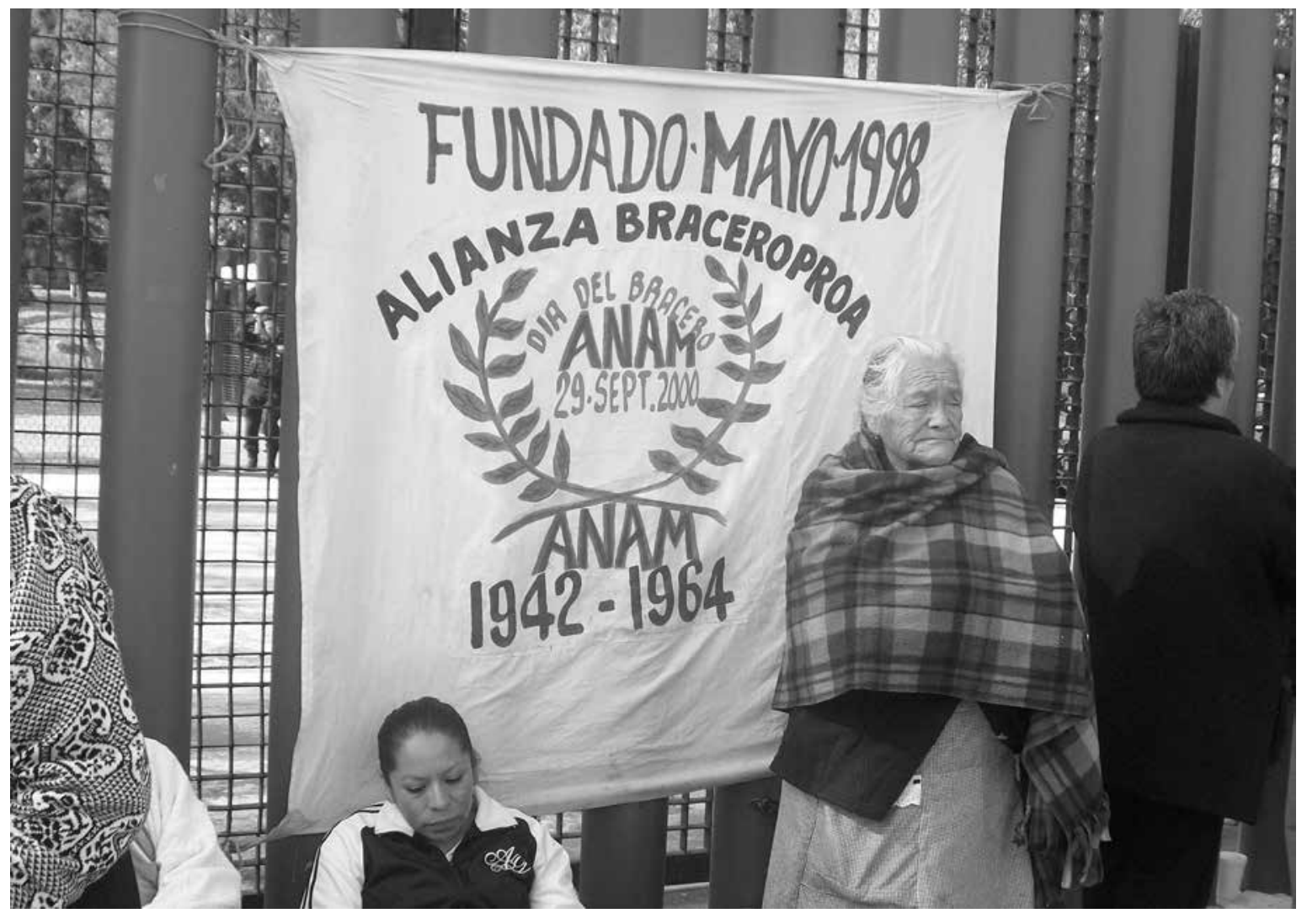

PHILIPPE SCHAFFHAUSER • Plantón de la asociación Braceroproa afuera del Palacio Legislativo de San Lázaro, Ciudad de México, 29 de septiembre de 2011. 
debates, tampoco en los consensos y acuerdos que se toman. Apuestan a que sus traductores encuentren un término medio con los propietarios del problema. En definitiva, ellos trazan la geometría institucional del problema e introducen matices y sesgos para solucionarlo: la cronología de los hechos, las reglas de operación a espaldas de los propios braceros y sus organizaciones para determinar quiénes son braceros y quiénes no. Asimismo, tuvieron la última palabra —obviamente, mediante otras gestiones con el ejecutivo federal y la SHCP- para determinar el monto total del apoyo social, así como las resoluciones legales sobre el finiquito del conflicto que implicaron: 1) no investigar ni demandar penalmente a los responsables del fraude, y 2) sustituir el pago del fondo de ahorro por el pago de un apoyo social.

\section{Comentarios finales}

"Portadores", "traductores" y "propietarios" de un problema público no son categorías sociales, sino analíticas (Becker, 2006; Schaffhauser, 2016: 35-82). Han de entenderse como funciones que ocupan sujetos dentro de un proceso social de protesta. Crean en la mente del investigador un espacio epistémico para analizar y comprender mejor la construcción moral de las políticas públicas. Dichas categorías construyen un puente entre tres niveles engarzados de la realidad: lo natural, lo cultural y lo epistémico. El interaccionismo simbólico, en tanto expresión del pragmatismo en ciencias sociales (Collins, 2009: 397-460), añade una dimensión más: la posibilidad de construir categorías, nociones y conceptos ad hoc que articulan estos tres niveles de la realidad natural, cultural y epistémica. Por ello, los términos "portadores", "traductores" y "propietarios" son metáforas para ilustrar uno u otro registro de la realidad. Si el interaccionismo simbólico puede combinar estos tres niveles es precisamente porque guarda una relación de sumo grado con el pragmatismo (Schaffhauser, 2016), cuya característica magna es ser una filosofía de la continuidad, es decir, de la significación en proceso. En este sentido, el problema bracero no comienza con el Programa Bracero en 1942, sino, tal vez, con el sistema de enganches de trabajadores agrícolas para Estados Unidos y Guatemala durante el Porfiriato (1880-1910) y con el primer Programa Bracero entre México y Estados Unidos, en los últimos años de la Primera Guerra Mundial (Alanís, 1999).

A lo largo de este artículo he intentado mostrar lo que son en realidad las políticas públicas desde el punto de vista de quienes solicitan su implementación, esto es, la presentación e integración socialmente construidas de problemas sociales. La dimensión pública de éstas constituye, sin duda, el epicentro de este problema, ya que pone de relieve la transformación de masas de anónimos en públicos específicos. Es interesante señalar, en este sentido, que el movimiento bracero ha logrado, por medio de la participación y acción de las organizaciones civiles que lo portan, una reapropiación de la palabra "bracero", otrora despectiva, para designar un nuevo público que subió al escenario político mexicano, los ex braceros. En realidad, se trata de nuevos braceros, según el concepto de William James (1999) acerca de los seres nacidos dos veces (Schaffhauser, 2012: 238-241). Volvieron a nacer. Su pasado se ha convertido en causa para construir su futuro y el de sus familias. Lograron cambiar con creces su estatuto simbólico de chivo expiatorio (Girard, 1986) por la figura del vulnerable, que pone de relieve las carencias de las instituciones para atender al sector de la tercera edad, con el agravante de la disparidad de trato que existe entre el campo y la ciudad.

Ahora bien, entre estas aspiraciones, el entusiasmo pautado de los braceros que las acompaña y la manera en que han sido traducidas a políticas públicas en el programa de apoyo social a braceros existe 
una brecha que consiste en la construcción de un camino angosto de interacciones e interlocuciones, que desemboca en la definición de un coto de poder en el que sesionan los propietarios del problema bracero en México. Como se ha dicho antes, algunos son auténticos — proceden de la base del movimiento de los braceros y fueron en su momento portadores, o mejor dicho, coportadores del problema, por ser familiares de braceros-, en tanto que otros aparecen en calidad de advenedizos, cuya legitimidad descansa en las funciones políticas que ejercen o la autoridad moral o intelectual que representan. La carrera de estos hacedores de la política de atención a los braceros ilustra también el tema de cómo se construyen las políticas públicas en general. Nos da a conocer y entender otros aspectos sociales y políticos relacionados con la definición e implementación de las políticas públicas. Lejos de ser una respuesta natural a necesidades colectivas, cuya evaluación consiste sólo en medir la distancia entre el dicho y el hecho, y en analizar el grado de congruencia programática entre los antecedentes, el objetivo general, las metas particulares y los medios disponibles, las políticas públicas son, sobre todo, resultado de interacciones complejas que ponen de relieve la participación de agentes con distintos papeles — portación, traducción y apropiación-y señalan la emergencia de nuevos públicos involucrados en el debate institucional y ciudadano general. Las políticas públicas no son maquinaria institucional, racional y desencarnada al servicio del concepto abstracto de interés general, sino seres vivos en los que se actualiza la construcción de intereses colectivos, para permitir la legitimación de los públicos que son sus portadores.

Analizar la política pública de atención a braceros con cabeza fría, es decir, sólo a partir del quehacer de la Comisión Especial para Dar Seguimiento a los Fondos de los Trabajadores Mexicanos Braceros y del fideicomiso 2106, constituye, en este sentido, un error metodológico, y tal vez deriva en un problema moral para con los braceros, que consiste en pasar por alto su agencia en tanto sujetos de carne y hueso culturalmente situados, quienes, cual más, cual menos, originaron y construyeron su problema social, es decir, sentaron las bases para la creación de una política pública dirigida a ellos.

Las políticas públicas no nacen de la nada. Cuando son de índole social, no son favores políticos otorgados a los que menos tienen. Son conquistas sinuosas y a menudo efímeras. Favorecen la construcción provisional de un orden social y moral. El factor tiempo es importante: el programa bracero duró 22 años — o cinco lustros hasta 1967-, la falta de atención al reclamo de los braceros se extendió por 41 años, hasta el voto de la ley para crear el fideicomiso 2106, en 2005, y por último, el programa para instalarlo tuvo una duración de sólo siete años, ya que "oficiosamente" la política de atención a braceros está estancada desde finales de 2012.

La lucha de los ex braceros apunta también al reconocimiento de valores que porta el público de braceros, que giran en torno al concepto de recuperación de una dignidad perdida. De ahí se antoja la idea de analizar en investigaciones futuras este movimiento a la luz de "la sociología del desprecio" de Axel Honneth (2006), quien señala la importancia creciente del ágape - amor y empatía — en la orientación de las luchas sociales, es decir, la aceptación de nuevos actores en el escenario social y político, como los migrantes y los veteranos. Hasta ahora, todos los intentos para atender la situación de los braceros se han caracterizado por traducirla al campo económico del dinero, sin considerar la dimensión moral y emocional que constituye una parte esencial del problema. La idea de perjuicio o daño moral es ajena al lenguaje de las autoridades. Pagar un apoyo social a los ex braceros no ha sido suficiente para ganar su simpatía moral y sosegar la tensión existente entre ellos y el gobierno. Como bien dice el público de braceros: "no pedimos limosna sino justicia". La búsqueda de justicia se ha convertido en su imperativo categórico. D 


\section{Bibliografía}

Alanís Enciso, Fernando Saúl, 1999, El primer Programa Bracero y el gobierno de México, 1917-1918, El Colegio de San Luis, San Luis Potosí. Becker, Howard S., 2006, Outsiders. Hacia una sociología de la desviación, Siglo XXI Editores, México.

Bustamante, Jorge, 1976, “Espaldas mojadas, materia prima de la expansión del capitalismo norteamericano", en Cuadernos del Centro de Investigaciones Sociológicas, núm. 9, El Colegio de México, México.

Centro de Estudios de Finanzas Públicas (CEFP), 2008, “Impacto presupuestario 'Programa Bracero' 1942-1964”, Cámara de Diputados/H. Congreso de la Unión, México.

Collins, Randall, 2009, Cadenas de rituales de interacción, Anthropos, México.

Dewey, John, 2003, Le public et ses problèmes, Publications de l'Université de Pau/Éditions Léo Scheer, Pau.

Felstiner, William L. F., Richard Abel y Austin Sarat, 1980-1981, “The Emergence and Transformations of Disputes. Naming, Blaming, Claiming...”, en Law and Society Review, vol. 15, núms. 3-4, pp. 631-654.

Girard, René, 1986, El chivo expiatorio, Anagrama, Barcelona.

Gusfield, Joseph R., 1981, The Culture of Public Problems. Drinking-Driving and The Symbolic Order, University of Chicago Press, Chicago.

Gutiérrez Méndez, Ventura, 2011, "Yo fui bracero: nos desnudaban para luego fumigarnos”, ponencia presentada en el I Coloquio Internacional sobre el Programa Bracero "Retrospectiva y nuevos enfoques", Universidad Nacional Autónoma de México, 30 de septiembre, México.

Honneth, Axel, 2006, La société du mépris. Vers une nouvelle théorie critique, La Découverte, París.

James, William, 1999, Las variedades de la experiencia religiosa. Estudio de la naturaleza humana, Península, Barcelona.

Joas, Hans, 1999, La créativité de l'agir, Cerf, París.

2002, Creatividad, acción y valores: hacia una teoría sociológica de la contingencia, Universidad Autónoma Metropolitana-Iztapalapa, México.

Mead, George Herbert, 1990, Espiritu, persona y sociedad. Desde el punto de vista del conductismo social, Paidós, México.

Neveu, Erik, 1999, “L’approche constructiviste des 'problèmes publics'. Un aperçu des travaux anglo-saxons”, en Études de Communication, núm. 22, pp. 41-58.

Park, Robert Ezra, 1996, "La masa y el público. Una investigación metodológica y sociológica”, en Revista Española de Investigaciones Sociológicas, vol. 74, núm. 96, pp. 361-423.

Proctor, Robert, 2008, Agnotology. The Making and Unmaking of Ignorance, Stanford University Press, San Francisco.

Schaffhauser, Philippe, 2011, "Veteranos del Norte. El movimiento de los ex-braceros: un acercamiento a la sociología de la tercera edad y su empoderamiento", avance de investigación, El Colegio de Michoacán, Zamora.

__ 2012, "Consecuencias del Norte: el movimiento de los ex braceros (1942-1964) como hecho cultural”, en Yerko Castro Neira (ed.), La migración y sus efectos en la cultura, Consejo Nacional para la Cultura y las Artes, México, pp. 211-245.

__ 2016, Los usos del pragmatismo: un paseo por las ciencias sociales entre México y Estados Unidos, siglos Xx y XXI, El Colegio de Michoacán, Zamora.

Sennett, Richard, 2009, El artesano, Anagrama, Barcelona.

\section{Entrevistas}

Integrante de Ex Braceros en Lucha, Zacatecas, Zacatecas, 18 de febrero de 2012. 